\title{
CDK2-dependent activation of PARP-1 is required for hormonal gene regulation in breast cancer cells
}

\author{
Roni H.G. Wright, ${ }^{1}$ Giancarlo Castellano, ${ }^{1}$ Jaume Bonet ${ }^{2}$ Francois Le Dily, ${ }^{1}$ Jofre Font-Mateu, ${ }^{1}$ \\ Cecilia Ballaré, ${ }^{1}$ A. Silvina Nacht, ${ }^{1}$ Daniel Soronellas, ${ }^{1}$ Baldo Oliva, ${ }^{2}$ and Miguel Beato ${ }^{1,3}$ \\ ${ }^{1}$ Centre de Regulació Genòmica (CRG), Barcelona E-08003, Spain; ${ }^{2}$ Structural Bioinformatics Laboratory (SBI), Universitat \\ Pompeu Fabra (UPF), Barcelona E-08003, Spain
}

Eukaryotic gene regulation implies that transcription factors gain access to genomic information via poorly understood processes involving activation and targeting of kinases, histone-modifying enzymes, and chromatin remodelers to chromatin. Here we report that progestin gene regulation in breast cancer cells requires a rapid and transient increase in poly-(ADP)-ribose (PAR), accompanied by a dramatic decrease of cellular NAD that could have broad implications in cell physiology. This rapid increase in nuclear PARylation is mediated by activation of PAR polymerase PARP-1 as a result of phosphorylation by cyclin-dependent kinase CDK2. Hormone-dependent phosphorylation of PARP-1 by CDK2, within the catalytic domain, enhances its enzymatic capabilities. Activated PARP-1 contributes to the displacement of histone $\mathrm{H} 1$ and is essential for regulation of the majority of hormoneresponsive genes and for the effect of progestins on cell cycle progression. Both global chromatin immunoprecipitation (ChIP) coupled with deep sequencing (ChIP-seq) and gene expression analysis show a strong overlap between PARP-1 and CDK2. Thus, progestin gene regulation involves a novel signaling pathway that connects CDK2-dependent activation of PARP-1 with histone H1 displacement. Given the multiplicity of PARP targets, this new pathway could be used for the pharmacological management of breast cancer.

[Keywords: mouse mammary tumor virus; progesterone receptor; transcriptional regulation; histone H1; PARP-1; chromatin remodeling]

Supplemental material is available for this article.

Received March 30, 2012; revised version accepted July 11, 2012.

Eukaryotic gene regulation requires that transcription factors gain access to genomic information via processes involving activation and targeting of kinases, histonemodifying enzymes, and chromatin remodelers to chromatin. Post-translational modification of chromatin and chromatin-modifying enzymes is a key component of gene regulation mechanisms; however, in this context, one such modification, poly-(ADP)-ribosylation (PARylation) catalyzed by the PAR polymerase (PARP) family of enzymes, remains poorly characterized (Chambon et al. 1963; Ame et al. 2004). PARP-1 and PAR play a role in regulating chromatin structure in various physiological contexts and after DNA damage, as PARylation of histones destabilizes nucleosomes (Poirier et al. 1982; Kraus and Lis 2003). Although PARP-1 was identified as the transcription factor TFIIC (Slattery et al. 1983), its activation and role in transcriptional regulation in the absence of DNA

${ }^{3}$ Corresponding author

E-mail miguel.beato@crg.es

Article is online at http://www.genesdev.org/cgi/doi/10.1101/gad.193193.112. damage remained unclear (Tulin et al. 2002; Kraus and Lis 2003; Kim et al. 2004; Parvi et al. 2005). Here we report that progestin gene regulation and subsequent cell proliferation in breast cancer cells require a rapid and transient increase in PAR, mediated by activation of PARP-1. PARP-1 activation is the result of phosphorylation by the hormoneactivated cyclin-dependent kinase CDK2 at two consecutive serine residues, leading to enhanced PARylation capabilities. As PARP-1 is required for ligand-induced transcriptional activation following $17 \mathrm{~b}$ estradiol and retinoic acid treatment (Parvi et al. 2005; Ju et al. 2006) and interacts with progesterone receptor (PR) (Sartorius et al. 2000), we demonstrate the mechanism of PARP-1 activation in breast cancer cells. PARP-1 activation contributes to displacement of histone $\mathrm{Hl}$, an essential step for regulation of the majority of hormone-responsive genes and for the effect of progestins on cell cycle progression. Both global chromatin immunoprecipitation (ChIP) coupled with deep sequencing (ChIP-seq) and gene expression analysis show a strong overlap between PARP-1 and CDK2. Thus, progestin gene regulation involves a novel signaling pathway 
connecting CDK2-dependent activation of PARP-1 with histone $\mathrm{H} 1$ displacement, offering a potential target for endocrine control of breast cancer progression.

\section{Results}

PAR levels dramatically increase following hormone treatment

First, we estimated the levels of PAR and PARP-1 by immunofluorescence at different time points after hormone treatment of T47D-MTVL $\left(\mathrm{T}_{4} \mathrm{D}^{\mathrm{M}}\right)$ breast cancer cells that carry a single integrated copy of a luciferase transgene driven by the mouse mammary tumor virus (MMTV) promoter (Truss et al. 1995). Nuclear PAR levels increased dramatically after treatment with the synthetic progesterone analog R5020 for 15 min (Fig. 1A, left panel). Levels of PAR markedly increased 5 min following hormone addition, remained high for $30 \mathrm{~min}$, and returned to basal values after $60 \mathrm{~min}$ (Fig. 1B, top panel). The increase in PAR and PARylated proteins following hormone treatment was blocked by the PARP inhibitor $3 \mathrm{AB}$ (Fig. 1B, top panel, dashed line; Supplemental Fig. S1A). Concomitantly with the increase in PAR, the levels of PARP substrate NAD dropped after progestin treatment (Fig. $1 \mathrm{~B}$, bottom panel). The decrease in NAD levels was due to PARP activity, as it was abrogated by 3 AB. (Fig. 1B, bottom panel, dashed line). Thus, breast cancer cells respond to progestin treatment with a rapid and transient increase in PARylation of nuclear proteins catalyzed by the hormonal activation of members of the PARP family.

Activation of PARP plays a role in induction of the progesterone reporter gene in $\mathrm{T} 47 \mathrm{D}^{\mathrm{M}}$ cells. The 14 -fold increase in MMTV-luc transcription observed after $6 \mathrm{~h}$ of hormone treatment was significantly compromised following prior incubation with PARP inhibitor $3 \mathrm{AB}$ in a dose-dependent manner (Supplemental Fig. S1B). Similar results were observed with the PARP inhibitors PJ34 and NAP (Supplemental Fig. S1C). To date, 17 PARP family members have been identified, although PARP- 1 is responsible for $\sim 90 \%$ of PAR formed in cells (Ame et al. 2004). To confirm that PARP-1 is indeed the PARP responsible for the increase in PAR levels observed following hormone treatment, we generated $\mathrm{T} 47 \mathrm{D}^{\mathrm{M}}$ cells depleted of PARP-1 by stable expression of a specific shRNA (Fig. 1C). We observed no phenotypic or growth abnormalities (Supplemental Fig. S2A,B) in PARP-1 knockdown cell lines; however, we did observe that the hormonal activation of the MMTV transgene was reduced by $>70 \%$ compared with control shRNA cell lines (Fig. 1D). In addition, the induction of endogenous progesterone target genes c-Fos, DUSP1, and EGFR was also significantly reduced in the PARP-1 knockdown cell lines (Fig. 1E). Treatment of $T 47 \mathrm{D}^{\mathrm{M}}$ cells with progestin induces a single round of proliferation, and this progestin-induced proliferation of $\mathrm{T} 47 \mathrm{D}^{\mathrm{M}}$ cells was compromised in the absence of PARP-1 (Fig. 1F; Supplemental Fig. S2D); therefore, we conclude that gene induction and activation of cell proliferation by progestin depend on PARylation and an increase in PARP-1 activity.
CDK2 activates PARP-1 in response

to hormone treatment

To test whether activation of PARP-1 is mediated by one of the hormone-activated kinases, we measured the effect of several kinase inhibitors on the formation of PAR after progestin treatment (Supplemental Table S1). Only Cdk2ii, an inhibitor of CDK2, significantly $(P<0.05)$ abrogated the levels of PAR following hormone treatment (Supplemental Fig. S3A). Notably, inhibitors of the damage kinases ATM and ATR did not inhibit hormone-dependent PAR accumulation, suggesting a distinct signaling cascade from that activated during DNA damage. CDK2 is rapidly activated by progesterone in $\mathrm{T} 47 \mathrm{D}^{\mathrm{M}}$ cells and plays an important role in hormone gene regulation (Lange 2008; Vicent et al. 2011).

To confirm that CDK2 is involved in hormonal activation of PARP-1, CDK2 was knocked down in T47D ${ }^{\mathrm{M}}$ cells using specific siRNA. Depletion of CDK2 compromised the hormone-induced PAR accumulation, as determined by either Western blotting or ELISA (Fig. 2A [cf. lanes 3 and 4], B, respectively). Thus, the increase in PAR levels observed as quickly as $5 \mathrm{~min}$ following hormone treatment is dependent on CDK2 activity. The observed decrease in cellular NAD levels following hormone treatment was also inhibited by the inhibition of CDK2 (Supplemental Fig. S3B).

CDK2 in complex with Cyclin A and PR is required for the activation of some progesterone target genes (Narayanan et al. 2005; Vicent et al. 2011). Therefore, we tested whether genes dependent on PARP-1 activity are similarly affected by inhibition of CDK2. Hormonal induction of the MMTV-luc transgene-in addition to endogenous genes c-FOS, DUSP1, and EGFR-was markedly inhibited in the presence of the CDK2 inhibitor (Fig. 2C,D, respectively). Hormonal PARP-1 activation could be direct, since PARP-1 and CDK2 specifically interact following hormone treatment (Fig. 2E), suggesting that PARP-1 is a direct target of hormone-activated CDK2. Interaction studies using HA-CDK2 truncations revealed a region of CDK2 between amino acids 150 and 200, comprising the second cyclin-binding domain $(\mathrm{CBD})$, as responsible for the interaction with PARP-1 (Fig. 2F). The use of GST-PARP-1 proteins revealed that the CDK2 interaction domain of PARP-1 resides within the automodification domain encompassing the BRCA1 C-terminal (BRCT) domain (amino acids 326-525), a known protein-protein interaction domain for other PARP-1-binding partners, including PARP2, DNA ligase III (Schreiber et al. 2002), XRCC1 (Masson et al. 1998), DNA Pol $\beta$ (Dantzer et al. 2000), histones, and transcription factors Oct1 and YY1 (Fig. 2G; Oei and Shi 2001).

CDK2 phosphorylates PARP-1, resulting in a more catalytically active enzyme

PARP-1 is phosphorylated by CDK2 in vitro (Fig. 3A), and sequential in vitro phosphorylation and PARylation assays demonstrated that phosphorylated PARP-1 had a higher auto-PARylation activity as compared with unphosphorylated PARP-1 (Fig. 3B, cf. lanes 1 and 3). The 
Wright et al.

\section{A}
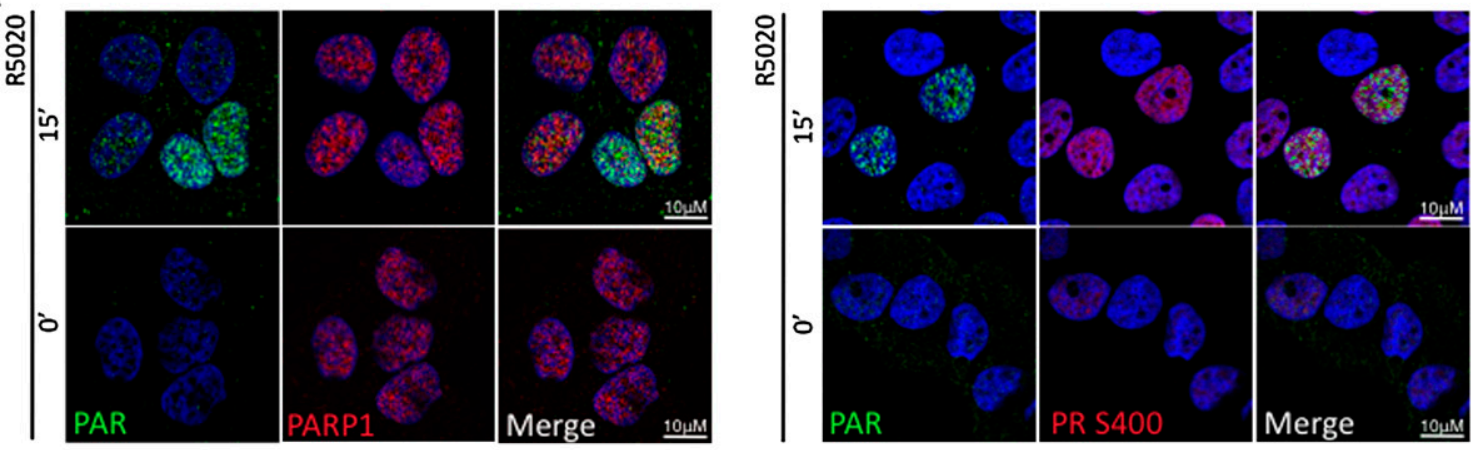

B
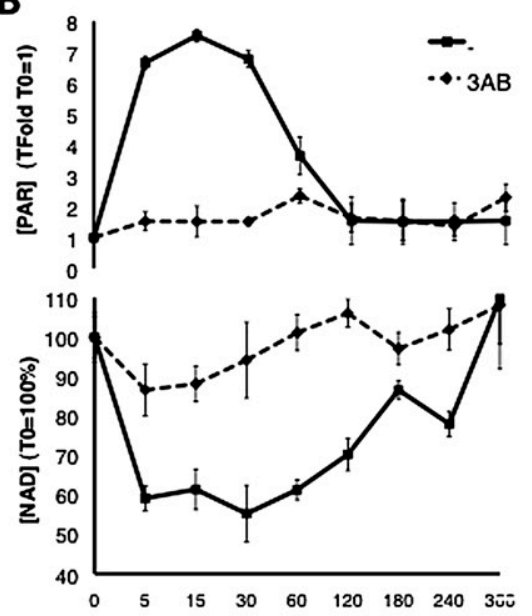

E

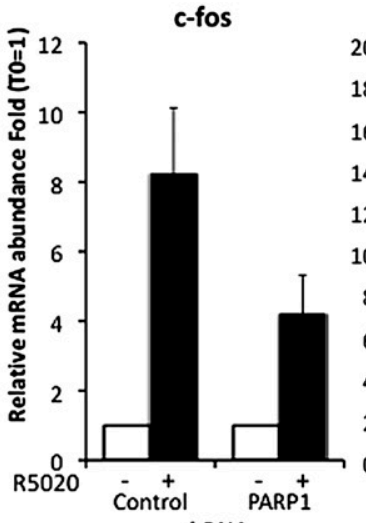

R5020 (minutes)
C

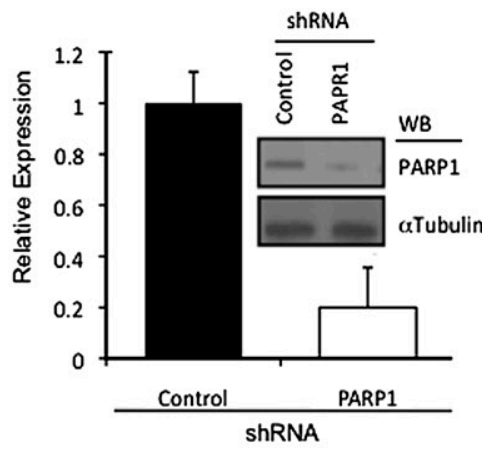

DUSP1

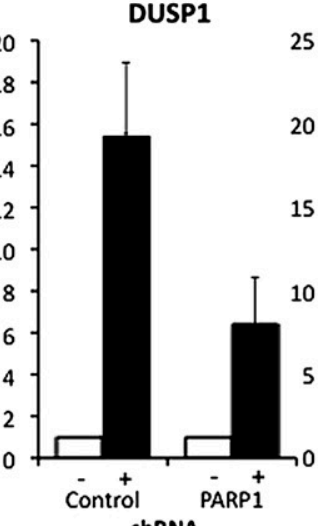

ShRNA

C
D

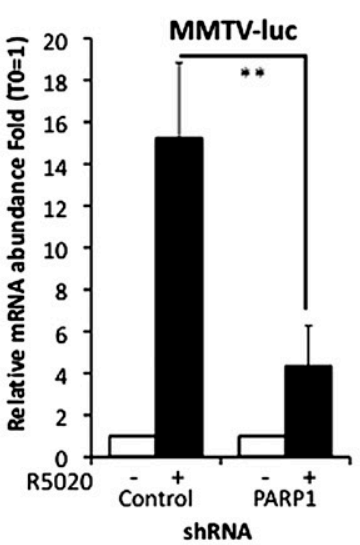

$\mathbf{F}$

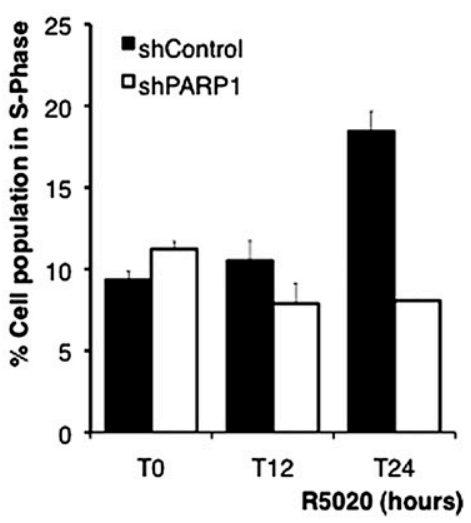

Figure 1. PAR rapidly accumulates following progestin stimulation. (A) PAR levels (green) increase in T47D ${ }^{\mathrm{M}}$ cells treated with R5020 for $15 \mathrm{~min}$. Levels of PARP-1 (left panels) and phosphorylated PR Ser400 (right panels), as a measure of cells responding to R5020, are shown in red. Bar, $10 \mu \mathrm{m}$. (B) Elevation in PAR levels (solid line), as measured by PAR-capture ELISA following R5020, is inhibited by $3 \mathrm{AB}$ (dashed line); hormone causes a concomitant decrease in cellular NAD levels (solid line, bottom panel), which is also 3ABdependent (dashed line, bottom panel). (C) PARP-1 knockdown by specific shRNA was confirmed by mRNA expression (histogram) and Western blotting (inset). R5020 induced higher mRNA levels from the MMTV-luc transgene $(D)$ as well as from $c$-fos, DUSP1, and EGFR $(E)$, all of which are abrogated in PARP-1 knockdown cell lines. $\left(^{\star \star}\right) P<0.01$. Error bars represent the SEM. $(F)$ The percentage of the cell population residing in S phase $24 \mathrm{~h}$ following R5020 was determined in PARP-1 knockdown and control cell lines.

trans-PARylation of histone $\mathrm{H} 1$ was also enhanced by prior phosphorylation of PARP-1 by CDK2 (Fig. 3B, cf. lanes 2 and 4). This enhancement of PARylation is not merely stabilized by the CDK2-PARP-1 interaction. It needs enzymatic activity, demonstrated by a kinase-dead CDK2, which is unable to enhance PARylation (Supplemental 

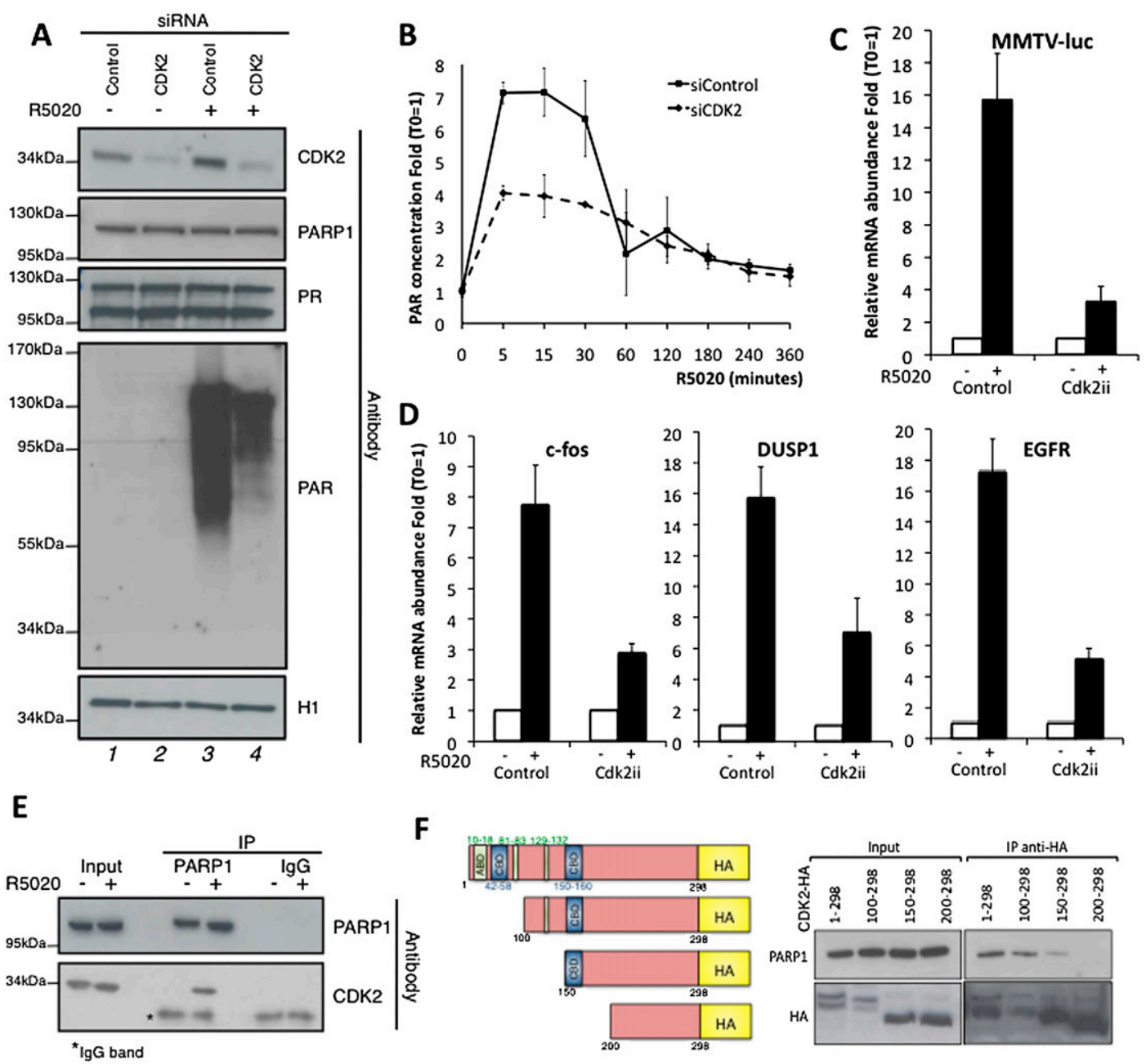

$\mathbf{F}$

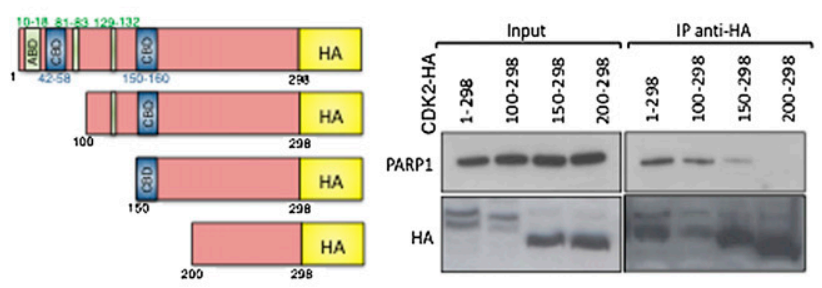

$\mathbf{G}$
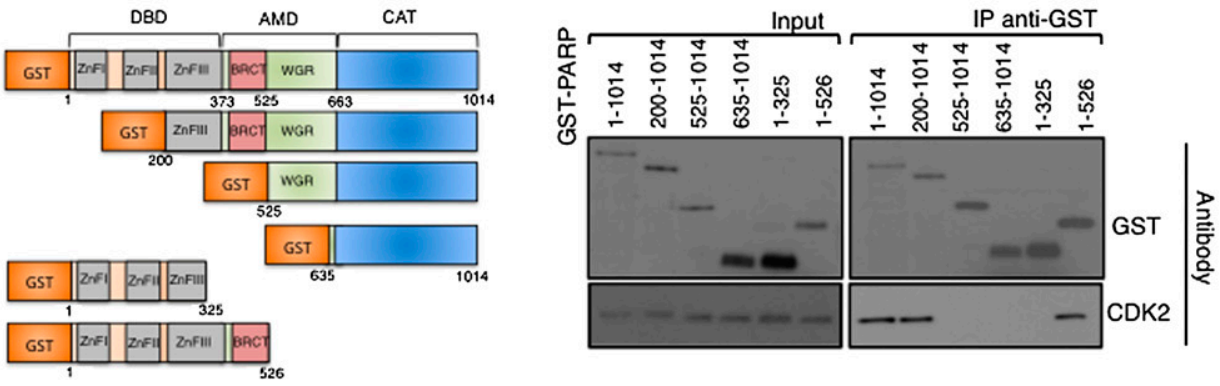

Figure 2. $\mathrm{CDK} 2$ is needed for PARP activation and hormonal activation. T47D ${ }^{\mathrm{M}}$ cell lysates transfected with either control or CDK2 siRNA for $48 \mathrm{~h}$ were harvested following incubation with R5020 for $15 \mathrm{~min}(+) .(A)$ The elevation in PAR levels following R5020 is dependent on CDK2 as determined by Western blotting using CDK2- and PAR-specific antibodies. Levels of PARP-1 and PR proteins are given as controls. (B) The increase in PAR levels, as measured by PAR-capture ELISA in T47D ${ }^{\mathrm{M}}$ cells treated with R5020 over time, is inhibited in T47D ${ }^{\mathrm{M}}$ cells treated with CDK2-specific siRNA compared with cells transfected with control siRNA. Error bars represent the SEM. Increased mRNA expression of the MMTV-luc transgene $(C)$ as well as $c$-fos, DUSP1, and EGFR $(D)$ in response to R5020 is dependent on CDK2 enzymatic activity, as the CDK inhibitor Cdk2ii blocks it. Error bars represent the SEM. (E) Immunoblot showing the hormone-dependent interaction of endogenous PARP-1 and CDK2 in T47D ${ }^{\mathrm{M}}$ cells treated with R5020 (+) for 30 min using PARP-1and CDK2-specific antibodies. (*) A nonspecific IgG band. (F) CDK2 interacts with PARP-1 via amino acids 150-200 partially encompassing the second CBD. (Left diagram) T47D ${ }^{\mathrm{M}}$ cells were transfected for $48 \mathrm{~h}$ with plasmids encoding HA-CDK2 truncations ([ABD] ATP-binding domain; numbers correspond to amino acid number). (Right panel) Cell extracts were prepared, immunoprecipitated using anti-HA-specific antibody, and probed for the interaction with PARP-1 by Western blotting. (G) PARP-1 interacts with CDK2 via the automodification domain encompassing the BRCT domain (amino acids 325-526). (Left diagram) Purified GST PARP-1 truncation proteins ( $\mathrm{ZnF}$ ]zinc finger; [BRCT] BRCT domain; [DBD] DNA-binding domain [AMD]; automodification domain; [CAT] catalytic domain; numbers correspond to amino acid number), purified from bacteria, were incubated with recombinant CDK2 for $2 \mathrm{~h}$ prior to incubation with GST beads. (Right) The interaction of GST-PARP-1 mutants with CDK2 was determined by Western blotting using GST- and CDK2-specific antibodies. 
A

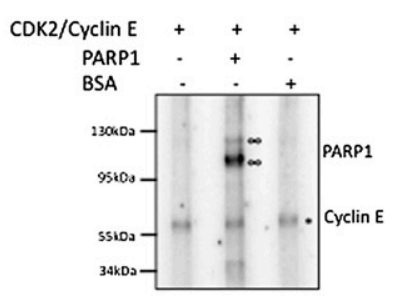

C

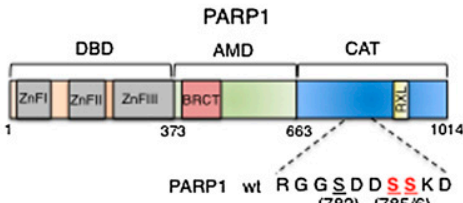
PARP1 wt RGGSDDSSKD

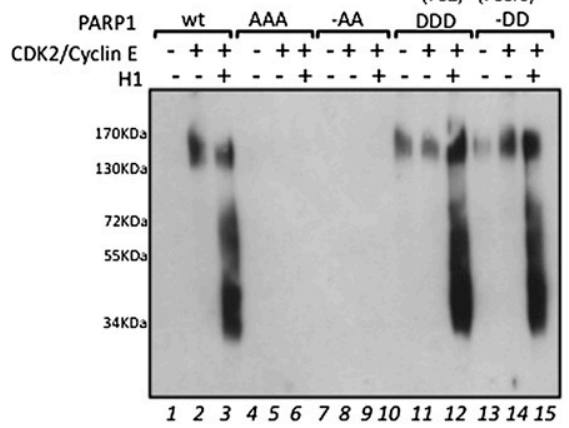

B CDK2/Cyclin E - + + +

PARP1 ++++

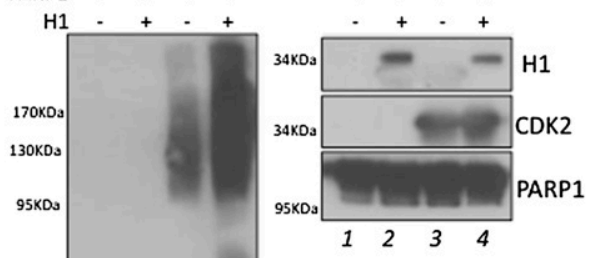

PAR

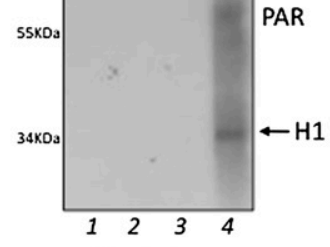

D siControl SiPARP1
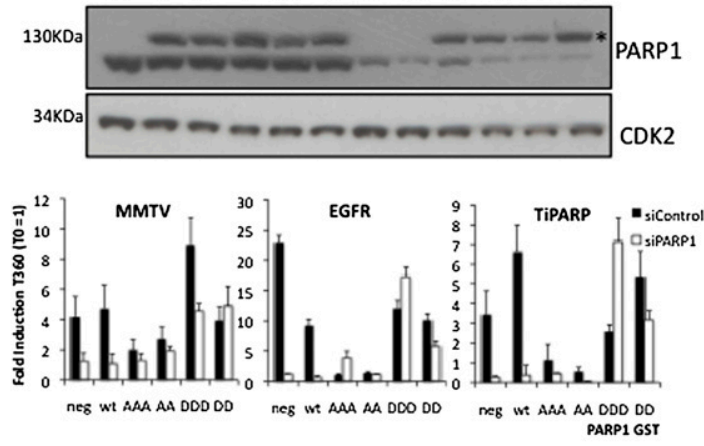

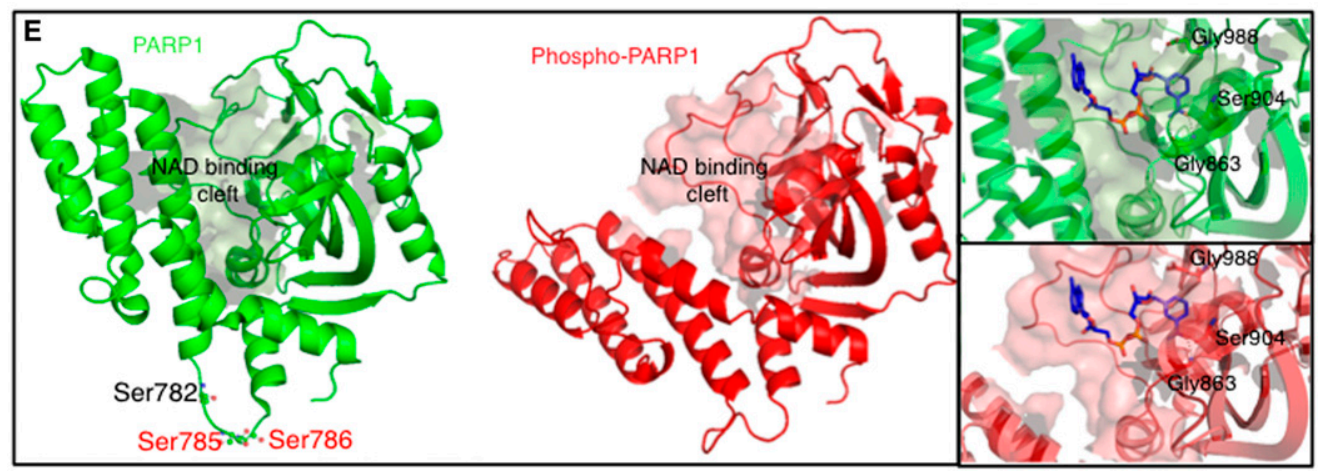

Figure 3. CDK2 phosphorylates PARP-1 in vitro and in vivo, leading to increased enzyme activity and predicted changes in the active site. (A) Recombinant CDK2 phosphorylates recombinant PARP-1 in vitro using g(p32)ATP as substrate, as visualized by SDS-gel electrophoresis and autoradiogram. $(\infty)$ Phosphorylated PARP- $\left.1 ;\left.\right|^{*}\right)$ phosphorylated Cyclin E as internal control. (B) CDK2 phosphorylation of PARP-1 enhances its auto- and trans-ADP-ribosylation activity as determined by sequential phosphorylation (in the presence or absence of CDK2/ Cyclin E) and PARylation (in the presence or absence of H1) assays. (Left panel) Levels of PAR produced were determined by Western blot using a PAR-specific antibody ( PARylation of $\mathrm{H1}$ is indicated by an arrow). The right panel shows a Western blot as control for the levels of the added proteins. $(C)$ The diagram indicates the locations of the hormone-induced CDK2-dependent (red) or CDK2-independent (black) PARP-1 phosphorylation sites and the cyclin-binding RXL domain. GST-PARP-1 mutants were expressed and purified from T47D ${ }^{\mathrm{M}}$ cells (Supplemental Fig. S5D,E). The ability of CDK2 to enhance the PARylation activity of GST-PARP-1 phospho-null mutants (PARP-1 AAA/AA; lanes 4-9) is significantly reduced compared with wild-type (wt) GST-PARP-1 (lanes 1-3), in contrast to the constitutively active PARylation capabilities observed using GST-PARP-1 phosphomimetic mutants (lanes 10-15), as determined by in vitro PARylation followed by immunoblot against PAR. ( $D$, top panel) The protein levels of both endogenous PARP-1 and GST-PARP-1 ( $\left.{ }^{\star}\right)$ following cotransfection of siRNA (either control or PARP-1-specific) and plasmids encoding GST-PARP-1 si-resistant mutants in T47D ${ }^{\mathrm{M}}$ cell lines were determined by Western blotting using PARP-1 antibody. CDK2 levels are shown as a loading control. (Bottom panel) Phosphomimetic, but not phosphonull mutations of PARP-1 are able to rescue hormone-induced gene response following PARP-1 knockdown. Hormone induction of the MMTV-luc transgene, EGFR, and TiPARP $6 \mathrm{~h}$ following hormone treatment in T47D ${ }^{\mathrm{M}}$ cell lines cotransfected with control siRNA (black bars) or PARP-1 siRNA (white bars) and GST-PARP-1 si-resistant rescue plasmids as described above. Values are given as a fold change over $\mathrm{T} 0=1 .(E)$ The opening of the catalytic domain due to the conformational change predicted by phosphorylation is clearly visible comparing the predicted structure of the unphosphorylated (green) or phosphorylated (red) PARP-1 catalytic domains. The right panels highlight residues Gly988, Ser904, and Gly863, essential for NAD (ligand shown) binding, residing within the NAD-binding cleft (amino acids 859-908 surface representation), which are not adversely affected by the shift in the catalytic domain induced by PARP-1 phosphorylation. 
Fig. S4B), although it interacts with PARP-1 (Supplemental Fig. S4C). Thus, phosphorylation of PARP-1 by CDK2 and not solely the interaction between these two proteins is essential for PARP-1 activation.

To test whether hormone-dependent CDK2-mediated PARP-1 phosphorylation occurs in vivo, PARP-1 from control T47D ${ }^{\mathrm{M}}$ cells or from cells treated with R5020 with or without prior incubation with the inhibitor Cdk2ii (Supplemental Fig. S5A) was analyzed by mass spectrometry. No significant phospho-peptides were found in the control sample, while three phospho sites were identified after hormone treatment, corresponding to Ser782, Ser785, and Ser786 of PARP-1. In cells treated with the CDK2 inhibitor, only the previously identified phospho site Ser782 (Mayya et al. 2009) was detected, suggesting that Ser785 and Ser786 are hormone-induced phospho sites dependent on CDK2 (Fig. 3C). PARP-1 contains a potential RXL domain (Supplemental Fig S5B) commonly found in CDK substrates facilitating proper substrate orientation and recognition by binding to the cyclin partner of the CDK (Adams et al. 1996). The phosphorylation of PARP-1 at Ser782, Ser785, and Ser786 by CDK2 is essential for the enhanced activity of PARP-1, as GST-PARP-1 Ser/Ala mutants greatly reduced the CDK2-enhanced activation of PARP-1 autoand trans-PARylation capabilities (Fig. 3C, cf. lanes 1-3 and 4-9). In contrast, phosphomimetic mutation of these sites (Ser/Asp) gave rise to a constitutively active PARP-1, the activity of which is not enhanced further by CDK2 phosphorylation (Fig. 3C, cf. lanes 1-3 and 13-15; Supplemental Fig. 5E). The PARylation capabilities of PARP1 782 phospho-null (A-) and phosphomimetic (D-) mutants showed no significant changes (data not shown). As shown by PARP-1 being required for progesterone induction of target genes (Fig. 1E), overexpression of phospho-null PARP-1 mutants acted as dominant-negative, inhibiting the progestin induction of target genes (Fig. 3D, black bars). Knockdown of PARP-1 resulted in impaired hormone induction (Fig. 3D, white bars), rescued by the addition of the si-resistant phosphomimetic PARP-1 but not the phospho-null mutants (Fig. 3D), confirming that the phosphorylation of PARP-1 is essential for the activation of downstream target genes.

We next asked whether this enhanced activity could be due to a structural change in the catalytic domain of PARP-1 induced by phosphorylation. The structure of the PARP-1 catalytic domain (Protein Data Bank [PDB] 3L3M) (Penning et al. 2005) was modeled mimicking phosphorylation at Ser782, Ser785, and Ser786 and revealed that the increase in negative charge results in the formation of a 3:10 helix (Lee et al. 2000), giving rise to a more open catalytic domain (Fig. 3E). This structural change significantly increases the exposition of the NAD acceptor site (Fig. 3E, surface representation) without affecting either the residues essential for NAD binding (Glu988, Ser904, or Gly863) (Fig. 3E, right panel) or the structural stability of the catalytic domain as a whole (Supplemental Fig. S6), thus supporting the hypothesis that phosphorylated PARP-1 is more catalytically active.
Hormone-induced gene regulation depends on both CDK2 and PARP-1 on a global scale

To obtain a global view of PARP-1 and CDK2 dependence in progesterone gene regulation, we performed gene expression microarrays with $\mathrm{T} 47 \mathrm{D}^{\mathrm{M}}$ cells untreated and treated with the progestin R5020 in the presence or absence of the PARP inhibitor $3 \mathrm{AB}$ or the CDK2 inhibitor Cdk2ii. We focused on the combined data set, which represents the genes that are significantly up-regulated or down-regulated in both arrays (Fig. 4A,B, Venn diagram). Eighteen percent of the genes in the combined list are dependent on CDK2 alone, and $12 \%$ depend on PARP exclusively. Only $15 \%$ of progestin-regulated genes in the combined list were independent of these two enzymes, while $85 \%$ (3219 genes in the combined data set) depended on either PARP-1 or CDK2 activity, with the majority $(55 \%)$ depending on both. A heat map representation (Fig. 4A) and correlation analysis (Supplemental Fig. S7C) clearly show that induced or repressed genes are also affected in a similar manner and to a similar extent by both inhibitors $(R=0.69)$. A similar pattern of PARP-1 and CDK2 dependence is found comparing up-regulated genes or down-regulated genes (Fig. 4C). Gene-specific mRNA determinations by RT-PCR were used to validate this dependence on the enzymatic activities of both CDK2 and PARP-1 and confirmed the array results (Fig. 4D). Consistent with progesterone-induced cellular proliferation, pathway analysis of PARP- and CDK2-dependent gene lists showed an enrichment of MAPK signaling and cancer pathways (Supplemental Table S3). Gene ontology (GO) term biological functional analysis was consistent with previous reports showing an enrichment of stress, transcription, cell signaling (intracellular signaling cascades, kinase cascades, and enzyme-linked receptor signaling), cell proliferation, and metabolic functions (Supplemental Tables S4-S7).

As previously published (Vicent et al. 2011), we detected recruitment of PR and CDK2 to the MMTV nucleosome B as early as $1 \mathrm{~min}$ after hormone induction (Fig. 5A). Since histone $\mathrm{H} 1$ is one of the main targets of PARP-1 and displacement of histone $\mathrm{Hl}$ is one of the initial steps in hormone-responsive promoters (Vicent et al. 2011), we measured H1 loading by ChIP. We confirmed that histone $\mathrm{H} 1$ is displaced from the MMTV promoter already $1 \mathrm{~min}$ after hormone treatment (Fig. 5A) and remains low until 30 min (Supplemental Fig. S8A). The concomitant recruitment of PARP-1 and CDK2 and H1 displacement were confirmed at other progesterone-binding sites (PRBs) (Fig. 5B, right panel). As it has been reported that PARP-1 and histone $\mathrm{H} 1$ are mutually exclusive at gene promoters (Krishnakumar et al. 2008), we performed a ChIP assay in PARP-1 knockdown cell lines. PARP-1 enzymatic activity is not essential for the initial recruitment of PARP1 or PR to target promoters, as depletion of PARP-1 protein (shRNA) or enzymatic activity (3AB) did not abrogate recruitment of PR to the MMTV promoter (Fig. 5C; Supplemental Fig. 8A, respectively). In marked contrast, the displacement of histone $\mathrm{H} 1$ is dependent on PARP-1 activity and hence PARylation, as hormone-induced H1 
Wright et al.

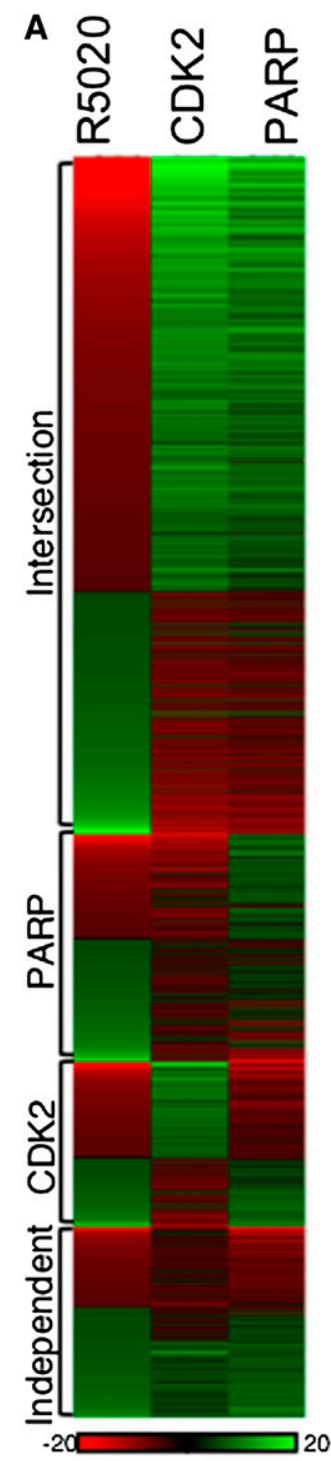

B

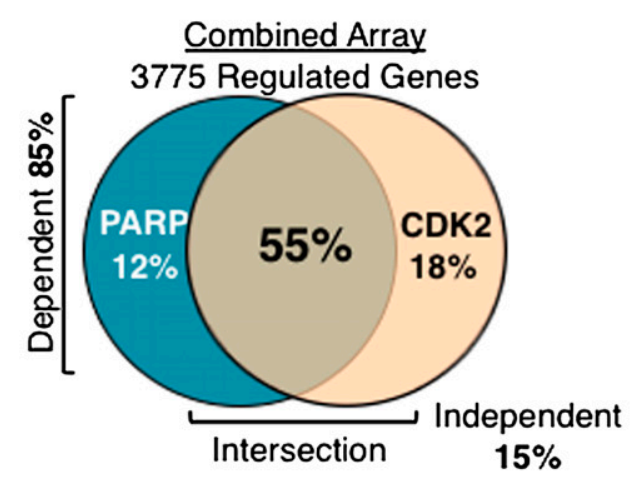

D
$\quad$ TIPARP
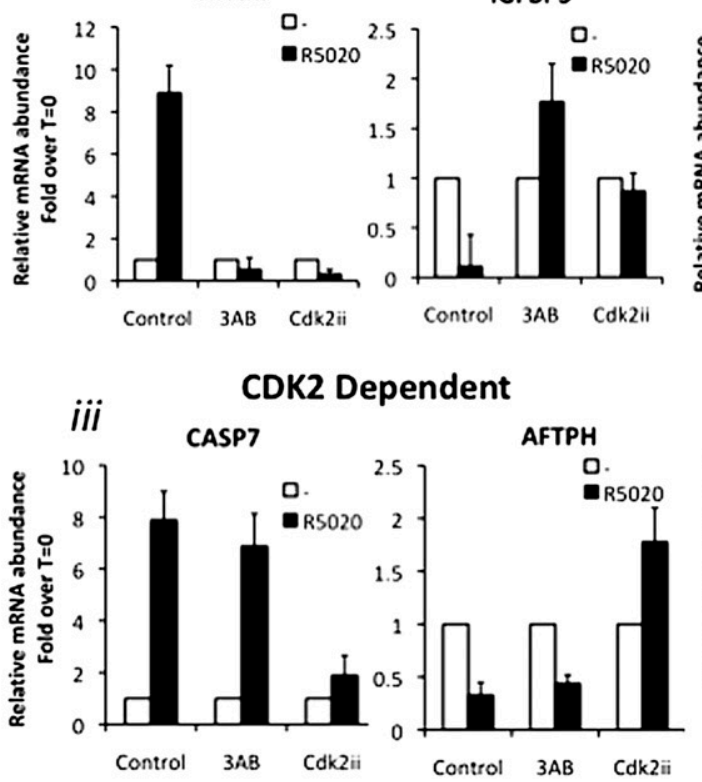

C

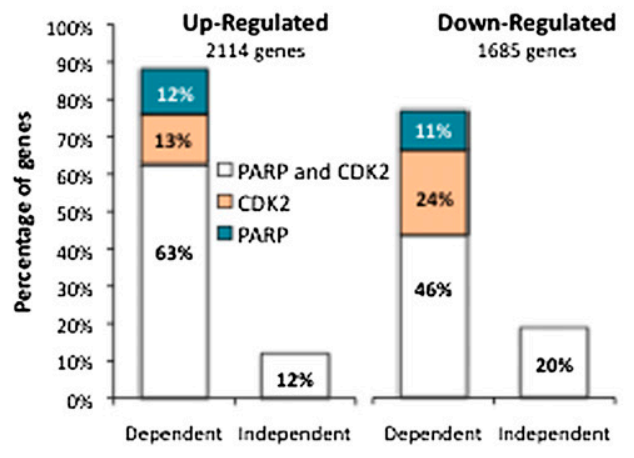

ii

PARP1 and CDK2 Independent

STAT1
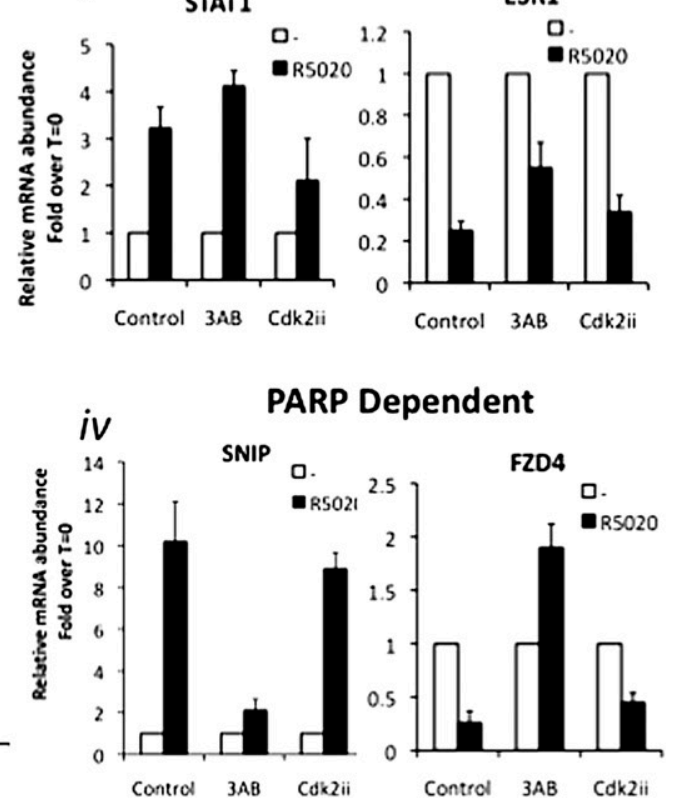

Figure 4. Global analysis of PARP-1 and CDK2 dependence of progestin gene regulation. $(A)$ The 3775 progestin-regulated genes representing the combined PARP-1 and CDK2 arrays correlate in their response to the inhibitors, as visualized by a heat map. (The color code in the samples treated with inhibitors reflects the changes relative to the sample treated only with R5020.) Summary of the individual inhibitor arrays (Supplemental Fig. S7A,B). (B) Venn diagram of progestin-regulated genes (bold; percentage of genes), indicating the dependence on CDK2 (18\%), PARP-1 (12\%), or both CDK2 and PARP-1 (intersection 55\%), or independent of the two enzymes $(15 \%)$. (C) Up-regulated and down-regulated progestin-dependent genes are similarly affected by the inhibition of PARP-1 and CDK2. ( $D$, panel i) mRNA expression levels of CDK2- and PARP-1-dependent genes TiPARP and IGFBP5 was determined by quantitative RT-PCR (qRT-PCR) in cells treated with R5020 for $6 \mathrm{~h}$ in the presence or absence of 3AB or CDK2ii. (Panel ii) mRNA expression levels of CDK2- and PARP-1-independent genes STAT1 and ESR1 was determined by qRT-PCR in cells treated with R5020 for $6 \mathrm{~h}$ in the presence or absence of $3 \mathrm{AB}$ or CDK2ii. (Panel iii) mRNA expression levels of CDK2-dependent genes CASP7 and AFTPH were determined by qRT-PCR in cells treated with R5020 for $6 \mathrm{~h}$ in the presence or absence of $3 \mathrm{AB}$ or CDK2ii. (Panel iv) mRNA expression levels of PARP-1-dependent genes SNIP and FZD4 were determined by qRT-PCR in cells treated with R5020 for $6 \mathrm{~h}$ in the presence or absence of $3 \mathrm{AB}$ or CDK2ii (mean fold induction over T0 $\pm \mathrm{SEM}$ ).

removal is blocked in PARP-1-depleted cell lines (Fig. 5C, cf. lanes 1-4 and 5-8) and in cells treated with $3 \mathrm{AB}$ (Supplemental Fig. S8A). We confirmed by re-ChIP experiments that following hormone treatment, binding of PARP-1 and CDK2 takes place on the same promoter (Fig. 5D). Moreover, hormone-dependent recruitment of PARP-1 and CDK2 as well as H1 displacement were dependent on the catalytic activities of both enzymes, as they were blocked by prior treatment of $\mathrm{T} 47 \mathrm{D}^{\mathrm{M}}$ cells with either $3 \mathrm{AB}$ or Cdk2ii (Supplemental Fig. 8B). ChIPseq analysis with antibodies to PARP-1 and CDK2 was performed at 0, 5, and $30 \mathrm{~min}$ following R5020, and a few thousand new peaks were found after hormone treatment (Fig. 5E, table), showing a significant corecruitment of 


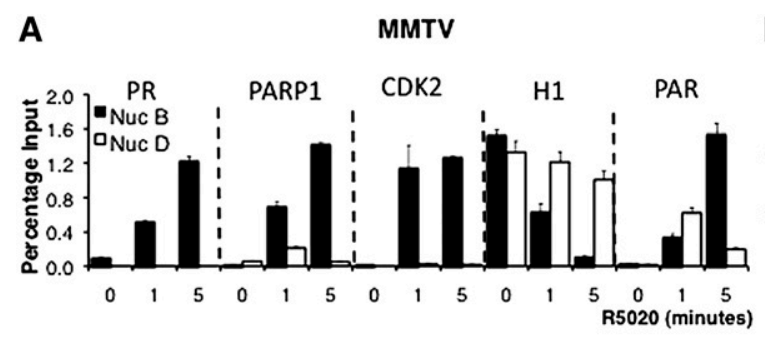

\section{B}

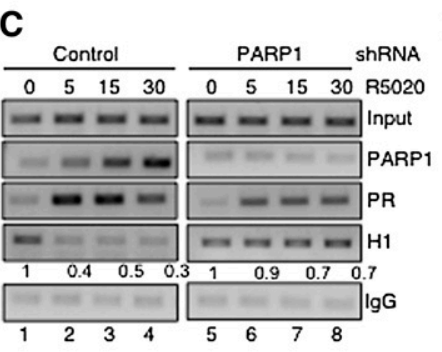

D

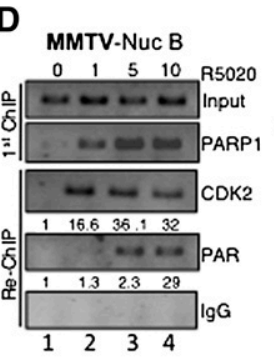

E
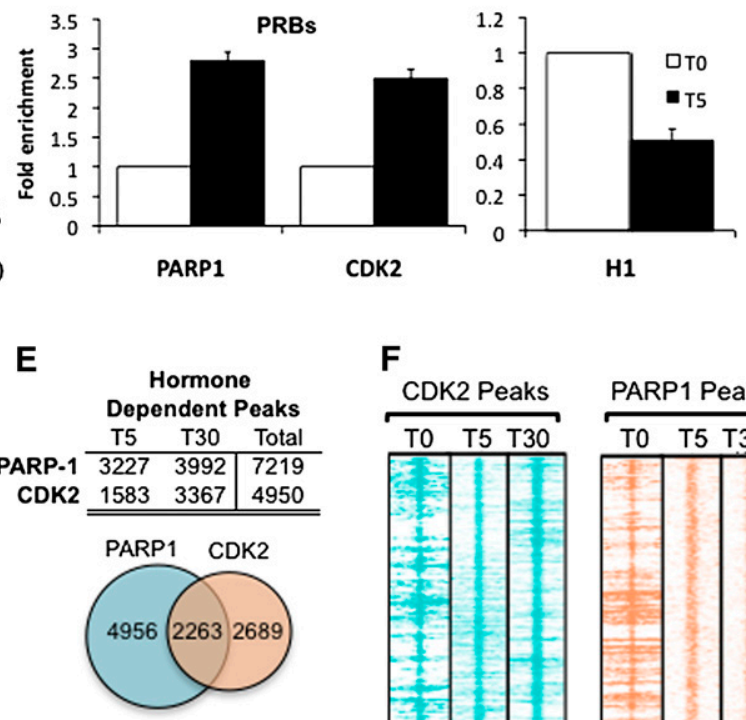

$\mathbf{F}$
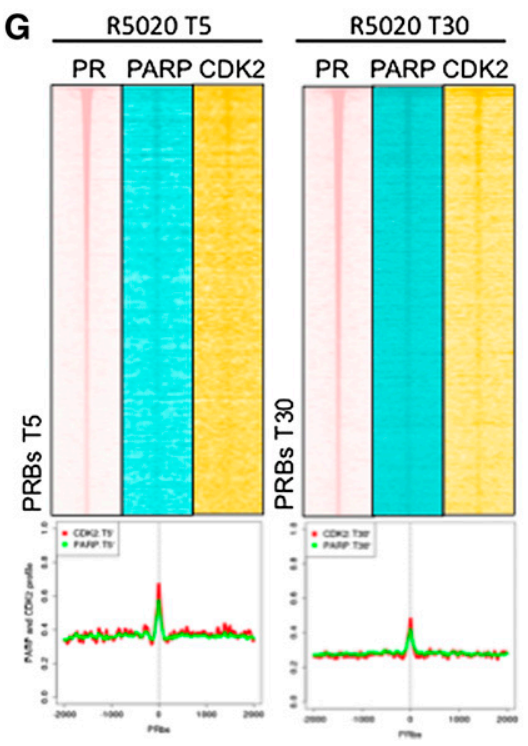

Figure 5. Global corecruitment of PARP-1 and CDK2 to chromatin and H1 displacement. $(A)$ The recruitment of PR, PARP-1, CDK2, and PAR specifically to the MMTV nucleosome B (Nuc B) and not nucleosome D (Nuc D) following R5020 treatment and the concomitant H1 displacement is shown by ChIP RT-qPCR at the indicated time points after hormone treatment. $(B)$ ChIP RT-qPCR shows the mean recruitment of PARP-1 and CDK2 in conjunction with H1 displacement following hormone treatment for 5 min to five different PR-binding sites. Error bars represent the SEM. (C) ChIP analysis in control or PARP-1 knockdown T47D ${ }^{\mathrm{M}}$ cells at different times following R5020 treatment demonstrates that R5020-induced H1 displacement from MMTV nucleosome B is dependent on PARP-1 enzymatic activity; compare lanes 1-4 and 5-8. The values below the H1 row show the H1 content relative to the 0 time point. (D) Re-ChIP: PARP-1-immunoprecipitated material used for a second immunoprecipitation with CDK2 or PAR antibodies confirmed co-occupancy of PARP and CDK2 as well as PARP and PAR on MMTV nucleosome B following R5020 treatment. RT-qPCR quantification is shown below the panels. $(E)$ The total number (table) and overlap/co-occupancy of both PARP-1 and CDK2 peaks identified following hormone treatment at T5 and T30 min (Venn diagram). (F) The chromatin occupancy of PARP-1 and CDK2 following hormone treatment significantly overlap. (Left) Raw sequencing tag distribution of PARP-1 in a region ( $\pm 2000 \mathrm{bp}$ ) centered on CDK2 peaks detected at 0,5 , and 30 min after hormone. (Right) Raw sequencing tag distribution of CDK2 in a region ( \pm 2000 base pairs $[\mathrm{bp}]$ ) centered on PARP-1 peaks detected at 0,5 , and 30 min after hormone treatment. (G) Heat map visualization of raw sequencing tag distribution of PR, PARP-1, and CDK2 at $5 \mathrm{~min}$ (left panel) and $30 \mathrm{~min}$ (right panel) after hormone treatment (R5020) in a region ( \pm 2000 bp) flanking PRBs. The PRBs are sorted according to their number of sequence tags in descending order. A quantitative profile of both PARP-1 and CDK2 distribution is shown below the heat maps.

both proteins (Fig. 5E, Venn diagram). Globally, for both PARP-1 and CDK2, we observed peaks recruited and maintained at 5 and 30 min following hormone treatment
(Supplemental Fig. 9). Visualization of PARP-1 occupancy on chromatin specifically on a $2-\mathrm{kb}$ region surrounding the CDK2 hormone-dependent peaks showed that PARP-1 
is enriched within these regions (Fig. 5F, left panel). Further supporting the cooperation of these two enzymes, CDK2 occupancy is also enriched on chromatin in regions surrounding PARP-1 hormone-dependent peaks (Fig. 5F, right panel). Both CDK2 and PARP1 were enriched around PRbinding sites, supporting a role of $\mathrm{PR}$ in recruiting these proteins to progestin-regulated regions (Fig. 5G).

\section{Discussion}

In recent years, a DNA damage-independent role for PARP-1 in both the activation and repression of transcription has emerged (Kraus and Lis 2003; Luo and Kraus 2012), which can or cannot require PARP-1 enzymatic activity (Hassa et al. 2003; Ju et al. 2004; Cohen-Armon et al. 2007). Several lines of evidence link PARP-1 with nuclear receptor (NR)-mediated transcription. PARP-1 inhibition has been shown to block estrogen receptor $\alpha$ $(\mathrm{ER} \alpha)_{-}$, androgen receptor $(\mathrm{AR})$-, retinoic acid receptor (RAR)-, and thyroid hormone receptor $\left(\mathrm{T}_{3} \mathrm{R}\right)$-dependent gene activation (Ju et al. 2006), but the role of PARP-1 in progesterone gene regulation has not been reported. Here we show that PARP-1 enzymatic activity is rapidly enhanced after progestin treatment of breast cancer cells and provide a molecular mechanism for this effect; namely, phosphorylation by hormone-activated CDK2. PARP-1 activation leads to a global increase in PAR levels that is essential for the induction or repression of the majority of progesterone-regulated genes. These findings differ from previous results by Parvi et al. (2005) showing that RAR-mediated transcription requires PARP-1, which, independent of its catalytic activity, converts Mediator from the inactive to the active state. Although Mediator and CDK2 both bind the BRCT domain of PARP-1, in progestin-treated breast cancer cells, the outcome is PARP1 phosphorylation and enhancement of its enzymatic activity, likely by opening the NAD-binding cleft of its catalytic domain. Additional experiments will be needed to explore whether activated PARP1 also has an effect on the Mediator state in progestin-treated breast cancer cells.

Kinase-induced activation of PARP-1 in the absence of DNA damage was demonstrated previously to be essential for expression of Elk1 target genes and for promoting cell proliferation (Cohen-Armon et al. 2007). In contrast with a previous study (Inbar-Rozensal et al. 2009), we observed that although PARP-1 is not essential for breast cancer cell growth in response to serum factors, it is indispensable for progesterone-induced cell proliferation after serum starvation. This effect of PARP-1 on hormonal response seems to be specific for PR, since ER $\alpha$ and PARP1 do not interact, and PR and PARP-1 expression levels positively correlate in proliferative lesions, whereas the levels of ER and PARP-1 do not (Ghabreau et al. 2004).

Although both PARP-1 and CDK2 have been previously implicated in the transcription of hormone-regulated genes (Parvi et al. 2005; Ju and Rosenfeld 2006; Moore and Weigel 2011; Vicent et al. 2011), the molecular mechanism of PARP-1 activation and the pathway connecting these two enzymes had not been established. Our results identify a new signaling pathway going from activated PR to activated CDK2 and PARP-1. Recently, the possibility of post-translational modification of PARP-1 mediating its activation has received considerable attention. Gagné et al. (2009) used a broad proteomic screen to identify several potential PARP-1 phosphorylation sites, including Ser372 and the residues Ser782/ Ser785 and Ser786 identified here. Subsequent biochemical studies have confirmed that phosphorylation of S372 and Thr373 by ERK1/2 enhances PARP-1 activation following DNA damage (Kauppinen et al. 2006). We provide evidence showing that in the absence of DNA damage, phosphorylation at Ser785 and Ser786 by CDK2 enhances PARP-1 activation in response to progesterone. The role of phosphatases in PARP-1 control is of potential interest, as the increase in PAR levels induced by progesterone is a transient event.

In addition to elucidating the molecular basis of hormonal PARP1 activation, we also provide a possible mechanism for the role of PARP1 in gene regulation. Both PARP-1 and CDK2 are recruited to the large majority of progestin target genes, where they cooperate in displacement of the linker histone $\mathrm{H} 1$. We showed previously that $\mathrm{H} 1$ displacement is the first step in progestinmediated gene regulation and that NURF and CDK2/ Cyclin E participate in this process, which takes place within 1 min after hormone addition (Vicent et al. 2011). We now show that the PARylation activity of PARP-1 is also required for the displacement of histone H1. Highly negatively charged PAR covalently attached to target proteins has the potential to alter protein-protein interactions and biochemical activities as well as the retention of proteins in the chromatin environment (Luo and Kraus 2012). As we observed a transient increase in PAR, the precise role of PAR hydrolysis by PAR glycohydrolase (PARG) to free either PAR or mono(ADP-ribose) will be of particular interest in the future.

We propose the following model (Fig. 6): (1) PARP-1 and CDK2/Cyclin E interact following progestin stimulation. (2) This interaction, via the BRCT domain of PARP-1 and the CBD of CDK2, facilitates the phosphorylation of PARP-1 at S785/S786. (3) Phosphorylation of PARP-1 results in a more open NAD-binding pocket within the catalytic domain, enhancing PARP-1 activity, leading to autoparylation. (4) PARP-1 and CDK2/Cyclin E are corecruited to chromatin, resulting in PARylation of chromatin proteins and chromatin opening via the displacement of histone H1. (5) The cooperation between CDK2 and PARP-1 is indispensable for regulation of many progestin target genes, as inhibition of PARP-1 and/or CDK2 blocks the downstream activation or repression of $85 \%$ of progestin target genes.

This study provides further insight into previous findings proposing a role for PARP-1 activation in signaling pathways required for downstream chromatin modification and gene regulation in the absence of DNA damage. Given the multiplicity of known PARP interactors in conjunction with the wide array of potential PARylation targets, it remains to be explored whether PARP-1 fulfils other functions in gene regulation and whether knowledge of this new pathway can be used for the 


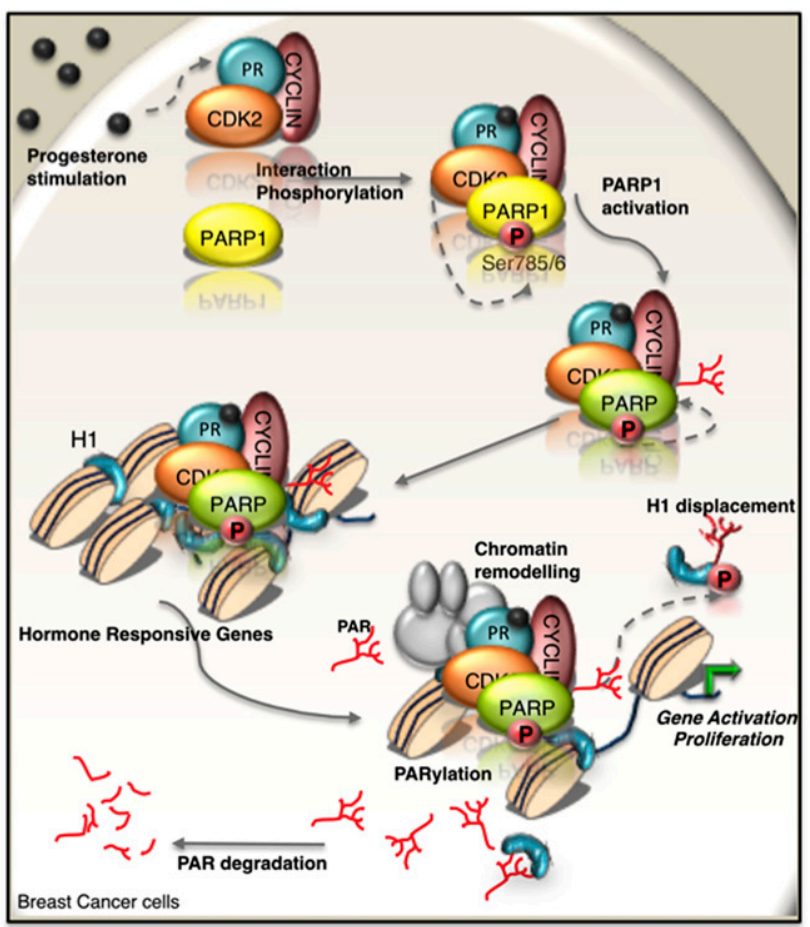

Figure 6. Model of progestin-induced PARP-1 activation by CDK2. PARP-1 activation via phosphorylation (S785/786) by CDK2 results in a more open catalytic domain and higher enzyme activity. This leads to a global increase in PAR levels, displacement of histone $\mathrm{H} 1$, and a more open chromatin environment, facilitating the recruitment of chromatin remodelers and transcriptional regulators essential for the induction or repression of the majority of progesterone-regulated genes.

pharmacological management of breast cancer (InbarRozensal et al.2009).

\section{Materials and methods}

\section{Cell culture}

$\mathrm{T}_{4} 7 \mathrm{D}^{\mathrm{M}}$ cells were used for all experiments unless otherwise stated. For hormone induction experiments, cells were grown in RPMI medium without Phenol Red, supplemented with 10\% dextran-coated charcoal-treated FBS (DCC/FBS) after $24 \mathrm{~h}$ in serum-free conditions; cells were incubated with R5020 (10 nM) or vehicle (ethanol) as described (Vicent et al. 2011). Inhibitor concentration and duration are given in Supplemental Table S1.

\section{PAR purification}

PAR was purified essentially as described (Aboul-Ela et al. 1988). Briefly, $5 \times 10^{6}$ human embryonic kidney (HEK) 293T cells were grown to confluency in $150-\mathrm{mm}$ plates. The growth medium was removed, and the cells were exposed to $200 \mathrm{~J} / \mathrm{m}^{2} \mathrm{UVB}$ irradiation. The medium was replaced, and $30 \mathrm{~min}$ later, the cells were harvested with trypsin. The resultant cell pellet was washed twice with PBS and precipitated with $20 \%$ final volume TCA. Following centrifugation at $1800 \mathrm{~g}$ for $10 \mathrm{~min}$ at $4{ }^{\circ} \mathrm{C}$, pellets were washed with $20 \%$ TCA and twice with $100 \%$ ethanol and airdried. The pellets were resuspended in $1 \mathrm{M} \mathrm{KOH}$ and $50 \mathrm{mM}$ EDTA and vortexed to mix. Extracts were then incubated for $2 \mathrm{~h}$ at $60^{\circ} \mathrm{C}$ with gentle agitation. A DHBB column was equilibrated with AAGE9 buffer (250 mM ammonium acetate at $\mathrm{pH} 9.0,6 \mathrm{M}$ guanine $\mathrm{HCl}$ ). Samples were passed through the column twice, and the column was then washed with AAGE9 buffer before a final wash of $1 \mathrm{M}$ ammonium acetate ( $\mathrm{pH}$ 9.0). PAR was eluted from the resin with water, lyophilized overnight, and stored at $-80^{\circ} \mathrm{C}$ until required.

\section{In vitro PARylation assay}

Unless otherwise indicated, the standard reaction contained $500 \mu \mathrm{g}$ of wild-type PARP-1 (Trevigen) or $1 \mu \mathrm{g}$ of GST-PARP-1 phosphomutants purified from mammalian cells previously phosphorylated in vitro by CDK2 as described (Supplemental Material). One-hundred micrograms of histone H1 (Millipore) and $200 \mathrm{ng}$ of activated DNA were incubated in PARP-1 reaction buffer $(400 \mu \mathrm{M}$ NAD, $50 \mathrm{mM}$ Tris-HEPES at $\mathrm{pH} 8.0,0.15 \mathrm{mM}$ $\mathrm{KCl}, 10 \mathrm{mM} \mathrm{MgCl} 2$ ) for $30 \mathrm{~min}$ at $25^{\circ} \mathrm{C}$. The reactions were stopped by the addition of $4 \times$ SDS loading buffer and analyzed on SDS-PAGE and Western blot probing for the presence of PAR using PAR-specific antibodies.

\section{PAR-capture ELISA}

Hormone and inhibitor treatments (Supplemental Table S1) were carried out as described, and sample preparation was carried out as follows: At the required time point, cells were washed twice with ice-cold PBS and scraped in lysis buffer $(0.4 \mathrm{M} \mathrm{NaCl}, 1 \%$ Triton X-100) plus protease inhibitors. Cell suspensions were then incubated for $30 \mathrm{~min}$ on ice with periodic vortexing. The disrupted cell suspension was centrifuged at 10,000 for $10 \mathrm{~min}$ at $4^{\circ} \mathrm{C}$, and the supernatant was recovered, snap-frozen, and stored at $-80^{\circ} \mathrm{C}$ until required. Ninety-six-well black-walled plates were incubated with $2 \mathrm{ng} / \mu \mathrm{L}$ anti-PAR monoclonal antibody (Trevigen) in $50 \mathrm{mM}$ sodium carbonate (pH 7.6) overnight at $4^{\circ} \mathrm{C}$. The plates were washed once with PBS and blocked with blocking solution $(5 \%$ semiskimmed milk powder, $0.1 \%$ Tween 20, $25 \mathrm{mM}$ Tris at $\mathrm{pH} 7.4,150 \mathrm{mM} \mathrm{NaCl}$ ) for $1 \mathrm{~h}$ at room temperature. The plate was then washed four times in PBS and $0.1 \%$ Tween 20 . One-hundred microliters of each sample $(20 \mu \mathrm{g}$ of total protein) or a PAR standard was applied and incubated for $1.5 \mathrm{~h}$ at room temperature. The plate was washed four times with PBS and $0.1 \%$ Tween 20 and incubated with anti-PAR rabbit polyclonal antibody (Trevigen) for $1.5 \mathrm{~h}$ at room temperature. The plate was washed four times with PBS and $0.1 \%$ Tween 20 and incubated with anti-rabbit HRP conjugate secondary antibody (5\% semiskimmed dried milk) for $1.5 \mathrm{~h}$ at room temperature. The plate was washed six times with PBS and $0.1 \%$ Tween 20, and PAR was identified via incubation with TACs Sapphire (Trevigen) for $10 \mathrm{~min}$ in the dark. The reaction was terminated with $5 \%$ phosphoric acid, and the absorbance at 450 $\mathrm{nm}$ and $520 \mathrm{~nm}$ was recorded.

\section{NAD depletion assay}

T47D ${ }^{M}$ cells were either left untreated or treated with the inhibitor indicated (Supplemental Table S1) prior to R5020 addition as described. NAD concentration was determined as described (Jacobson and Jacobson 1976). At $\mathrm{T}=t$, cells were washed with ice-cold PBS and incubated in 0.5 M PCA for $20 \mathrm{~min}$ on ice. An equal volume of $\mathrm{KOH}(1 \mathrm{M}) / \mathrm{K}_{2} \mathrm{HPO}_{4}(0.33 \mathrm{M})(\mathrm{pH} 7.0)$ was added, and the samples were vortexed and incubated for $20 \mathrm{~min}$ on ice. Samples were spun at $10,000 \mathrm{rpm}$ for $2 \mathrm{~min}$ at $4^{\circ} \mathrm{C}$, and the supernatant was stored at $-20^{\circ} \mathrm{C}$. The quantification of NAD was carried out as follows: Samples were added to an equal volume of reaction buffer $(200 \mathrm{mM}$ Bicine at $\mathrm{pH} 7.8,1 \mathrm{mg} / \mathrm{mL}$ 
BSA, $1 \mathrm{M} \mathrm{EtOH}, 10 \mathrm{mM}$ EDTA at $\mathrm{pH}$ 8.0, 4 mM phenazine). Onetenth of the reaction volume of alcohol dehydrogenase was added and incubated for $30 \mathrm{~min}$ at $30^{\circ} \mathrm{C}$. The reaction was terminated with a $0.3 \times$ sample volume of $12 \mathrm{mM}$ iodoacetate, and the absorbance at $570 \mathrm{mM}$ was measured.

\section{Purification of HA-CDK2 proteins for in vitro PARylation assays}

HEK 293T cells were transfected with pCMV-neo-CDK2 HAwt (Addgene plasmid depository 1884) or pCMV-neo-CDK2HAdn (Addgene plasmid depository 1885). Cells were serially diluted, and positive clones were selected with G418 $(1 \mathrm{mg} / \mathrm{mL})$. Expression of CDK2-HAwt or CDK2-HAdn was confirmed by Western blot as described using HA-specific antibody (Abcam). Purification of CDK2-HA proteins was carried out under nondenaturing conditions as follows: Cell lysates from $6 \times 10^{6}$ cells were prepared and incubated with $100 \mu \mathrm{L}$ of prewashed anti-HA agarose slurry (Pierce, Thermo Scientific). Samples were incubated overnight at $4^{\circ} \mathrm{C}$ with gentle end-over-end mixing on a rocking platform. Agarose beads were washed three times with TBS-Tween $20(0.05 \%)$ prior to HA-protein elution using 1 $\mathrm{mg} / \mathrm{mL}$ HA-peptide (Pierce, Thermo Scientific) for $15 \mathrm{~min}$ at $30^{\circ} \mathrm{C}$.

\section{Generation of HA-CDK2 truncations for PARP-1 interaction studies}

CDK2 truncations, including the HA tag (Fig. 2F) PCR-amplified from pCMV-neo-CDK2-HA (Addgene plasmid depository 1884), were subcloned using BamHI into empty pCMV-neo. PCR primers are available on request. The correct orientation was confirmed by sequencing using the Bglob-intron-F sequencing primer (CTGGTCATCATCCTGCCTTT). T47D ${ }^{\mathrm{M}}$ cells were transfected as described with CDK2-HA-encoding plasmids; 48 $\mathrm{h}$ later, cell lysates were prepared and immunoprecipitated using anti-HA-specific antibody overnight at $4^{\circ} \mathrm{C}$ end over end. The interaction of the CDK2-HA truncated proteins with PARP-1 was detected by Western blot using PARP-1-specific antibody.

Additional methods are provided in the Supplemental Material.

\section{Acknowledgments}

We thank Valerie Schreiber for the PARP-1-GST plasmid (pBChPARP-1), and Guillermo Vicent, Luciano Di Croce, and Juan Valcárcel for their critical reading of and advice on the manuscript. Proteomics analyses were performed in the CRG/ UPF Proteomics Unit. The experimental work was supported by grants from the Departament d'Innovació Universitat i Empresa (DIUiE), Ministerio de Educación y Ciencia (MEC) BMC 200302902, Consolider (CSD2006-00049), Fondo de Investigación Sanitaria (FIS) PI0411605 and CP04/00087, FEDER BIO20080205, and EU IP HEROIC. R.H.G.W. planned and performed experiments and helped with the writing of the manuscript. G.C. and D.S. performed microarray and ChIP-seq data analysis. J.B. performed all protein modeling simulations, analysis, and data interpretation in the laboratory of B.O. F.L.D. performed all immunofluorescence experiments and assisted in the planning and writing of the manuscript. J.F.M. performed the in vitro phosphorylation assays. CDK2 inhibitor microarrays were performed by C.B. A.S.N performed ChIP experiments. B.O. performed all protein modeling simulations, analysis, and data interpretation. M.B. coordinated the project, planned the experiments, and wrote the manuscript. All authors discussed the results and commented on the manuscript.

\section{References}

Aboul-Ela N, Jacobson EL, Jacobson MK. 1988. Labeling methods for the study of poly- and mono(ADP-ribose) metabolism in cultured cells. Anal Biochem 174: 239-250.

Adams PD, Sellers WR, Sharma SK, Wu AD, Nalin CM, Kaelin WG Jr. 1996. Identification of a cyclin-cdk2 recognition motif present in substrates and p21-like cyclin-dependent kinase inhibitors. Mol Cell Biol 16: 6623-6633.

Ame JC, Spenlehauer C, de Murcia G. 2004. The PARP superfamily. Bioessays 26: 882-893.

Chambon P, Weill JD, Mandel P. 1963. Nicotinamide mononucleotide activation of new DNA-dependent polyadenylic acid synthesizing nuclear enzyme. Biochem Biophys Res Commun 11: 39-43.

Cohen-Armon M, Visochek L, Rozensal D, Kalal A, Geistrikh I, Klein R, Bendetz-Nezer S, Yao Z, Seger R. 2007. DNAindependent PARP-1 activation by phosphorylated ERK2 increases Elk1 activity: A link to histone acetylation. Mol Cell 25: 297-308.

Dantzer F, de La Rubia G, Menissier-De Murcia J, Hostomsky Z, de Murcia G, Schreiber V. 2000. Base excision repair is impaired in mammalian cells lacking poly(ADP-ribose) polymerase-1. Biochemistry 39: 7559-7569.

Gagné JP, Moreel X, Gagné P, Labelle Y, Droit A, Chevalier-Paré M, Bourassa S, McDonald D, Hendzel MJ, Prigent C, et al. 2009. Proteomic investigation of phosphorylation sites in poly(ADP-ribose) polymerase-1 and poly(ADP-ribose) glycohydrolase. J Proteome Res 8: 1014-29.

Ghabreau L, Roux JP, Frappart PO, Mathevet P, Patricot LM, Mokni M, Korbi S, Wang ZQ, Tong WM, Frappart L. 2004. Poly(ADP-ribose) polymerase-1, a novel partner of progesterone receptors in endometrial cancer and its precursors. Int $J$ Cancer 109: 317-321.

Hassa PO, Buerki C, Lombardi C, Imhof R, Hottiger MO. 2003. Transcriptional coactivation of nuclear factor- $\mathrm{kB}$-dependent gene expression by p300 is regulated by poly(ADP)-ribose polymerase-1. J Biol Chem 278: 45145-45153.

Inbar-Rozensal D, Castiel A, Visochek L, Castel D, Dantzer F, Izraeli S, Cohen-Armon M. 2009. A selective eradication of human nonhereditary breast cancer cells by phenanthridinederived polyADP-ribose polymerase inhibitors. Breast Cancer Res 11: R78. doi: 10.1186/bcr2445.

Jacobson EL, Jacobson MK. 1976. Pyridine nucleotide levels as a function of growth in normal and transformed 3T3 cells. Arch Biochem Biophys 175: 627-634.

Ju BG, Rosenfeld MG. 2006. A breaking strategy for topoisomerase II $\beta /$ PARP-1-dependent regulated transcription. Cell Cycle 5: 2557-2560.

Ju BG, Solum D, Song EJ, Lee KJ, Rose DW, Glass CK, Rosenfeld MG. 2004. Activating the PARP-1 sensor component of the groucho/TLE1 corepressor complex mediates a CaMKinase II $\delta$-dependent neurogenic gene activation pathway. Cell 119: 815-829.

Ju BG, Lunyak VV, Perissi V, Garcia-Bassets I, Rose DW, Glass CK, Rosenfeld MG. 2006. A topoisomerase II $\beta$-mediated dsDNA break required for regulated transcription. Science 312: $1798-1802$.

Kauppinen TM, Chan WY, Suh SW, Wiggins AK, Huang EJ, Swanson RA. 2006. Direct phosphorylation and regulation of poly(ADP-ribose) polymerase-1 by extracellular signal-regulated kinases 1/2. Proc Natl Acad Sci 103: 7136-7141.

Kim MY, Mauro S, Gevry N, Lis JT, Kraus WL. 2004. NAD ${ }^{+}$ dependent modulation of chromatin structure and transcription by nucleosome binding properties of PARP-1. Cell 119: 803-814. 
Kraus WL, Lis JT. 2003. PARP goes transcription. Cell 113: 677683.

Krishnakumar R, Gamble MJ, Frizzell KM, Berrocal JG, Kininis M, Kraus WL. 2008. Reciprocal binding of PARP-1 and histone $\mathrm{H} 1$ at promoters specifies transcriptional outcomes. Science 319: 819-821.

Lange CA. 2008. Integration of progesterone receptor action with rapid signaling events in breast cancer models. I Steroid Biochem Mol Biol 108: 203-212.

Lee KH, Benson DR, Kuczera K. 2000. Transitions from $\alpha$ to $\pi$ helix observed in molecular dynamics simulations of synthetic peptides. Biochemistry 39: 13737-13747.

Luo X, Kraus WL. 2012. On PAR with PARP: Cellular stress signaling through poly(ADP-ribose) and PARP-1. Genes Dev 26: $417-432$.

Masson M, Niedergang C, Schreiber V, Muller S, Menissier-de Murcia J, de Murcia G. 1998. XRCC1 is specifically associated with poly(ADP-ribose) polymerase and negatively regulates its activity following DNA damage. Mol Cell Biol 18: 3563-3571.

Mayya V, Lundgren DH, Hwang SI, Rezaul K, Wu L, Eng JK, Rodionov V, Han DK. 2009. Quantitative phosphoproteomic analysis of $\mathrm{T}$ cell receptor signaling reveals system-wide modulation of protein-protein interactions. Sci Signal 2: ra46. doi: 10.1126/scisignal.2000007.

Moore NL, Weigel NL. 2011. Regulation of progesterone receptor activity by cyclin dependent kinases 1 and 2 occurs in part by phosphorylation of the SRC-1 carboxyl-terminus. Int J Biochem Cell Biol 43: 1157-1167.

Narayanan R, Adigun AA, Edwards DP, Weigel NL. 2005. Cyclin-dependent kinase activity is required for progesterone receptor function: Novel role for cyclin A/Cdk2 as a progesterone receptor coactivator. Mol Cell Biol 25: 264-277.

Oei SL, Shi Y. 2001. Transcription factor Yin Yang 1 stimulates poly(ADP-ribosyl)ation and DNA repair. Biochem Biophys Res Commun 284: 450-454.

Parvi R, Lewis B, Kim TK, Dilworth FJ, Erdjument-Bromage $\mathrm{H}_{\text {, }}$ Tempst P, de Murcia G, Evans R, Chambon P, Reinberg D. 2005. PARP-1 determines specificity in a retinoid signaling pathway via direct modulation of mediator. Mol Cell 18: 8396.

Penning TD, Zhu GD, Gong J, Thomas S, Gandhi VB, Liu X, Shi Y, Klinghofer V, Johnson EF, Park CH, et al. 2005. Optimization of phenyl-substituted benzimidazole carboxamide poly(ADP-ribose) polymerase inhibitors: Identification of (S)-2-(2-fluoro-4-(pyrrolidin-2-yl)phenyl)-1H-benzimidazole4-carboxamide (A-966492), a highly potent and efficacious inhibitor. J Med Chem 53: 3142-3153.

Poirier GG, de Murcia G, Jongstra-Bilen J, Niedergang C, Mandel P. 1982. Poly(ADP-ribosyl)ation of polynucleosomes causes relaxation of chromatin structure. Proc Natl Acad Sci 79: 3423-3427.

Sartorius CA, Takimoto GS, Richer JK, Tung L, Horwitz KB. 2000. Association of the $\mathrm{Ku}$ autoantigen/DNA-dependent protein kinase holoenzyme and poly(ADP-ribose) polymerase with the DNA binding domain of progesterone receptors. J Mol Endocrinol 24: 165-182.

Schreiber V, Ame JC, Dolle P, Schultz I, Rinaldi B, Fraulob V, Menissier-de Murcia J, de Murcia G. 2002. Poly(ADP-ribose) polymerase-2 (PARP-2) is required for efficient base excision DNA repair in association with PARP-1 and XRCC1. I Biol Chem 277: 23028-23036.

Slattery E, Dignam JD, Matsui T, Roeder RG. 1983. Purification and analysis of a factor which suppresses nick-induced transcription by RNA polymerase II and its identity with poly (ADP-ribose) polymerase. I Biol Chem 258: 5955-5959.
Truss M, Bartsch J, Schelbert A, Hache RJ, Beato M. 1995. Hormone induces binding of receptors and transcription factors to a rearranged nucleosome on the MMTV promoter in vivo. $E M B O J$ 14: $1737-1751$.

Tulin A, Stewart D, Spradling AC. 2002. The Drosophila heterochromatic gene encoding poly(ADP-ribose) polymerase (PARP) is required to modulate chromatin structure during development. Genes Dev 16: 2108-2119.

Vicent GP, Nacht AS, Font-Mateu J, Castellano G, Gaveglia L, Ballare C, Beato M. 2011. Four enzymes cooperate to displace histone $\mathrm{H} 1$ during the first minute of hormonal gene activation. Genes Dev 25: 845-862. 


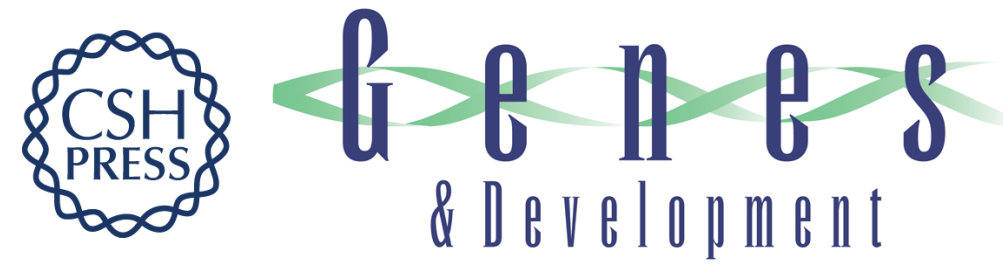

\section{CDK2-dependent activation of PARP-1 is required for hormonal gene regulation in breast cancer cells}

Roni H.G. Wright, Giancarlo Castellano, Jaume Bonet, et al.

Genes Dev. 2012, 26:

Access the most recent version at doi:10.1101/gad.193193.112

Supplemental
Material http://genesdev.cshlp.org/content/suppl/2012/08/28/26.17.1972.DC1

References This article cites 35 articles, 15 of which can be accessed free at:

http://genesdev.cshlp.org/content/26/17/1972.full.html\#ref-list-1

License

Email Alerting

Receive free email alerts when new articles cite this article - sign up in the box at the top

Service

right corner of the article or click here.

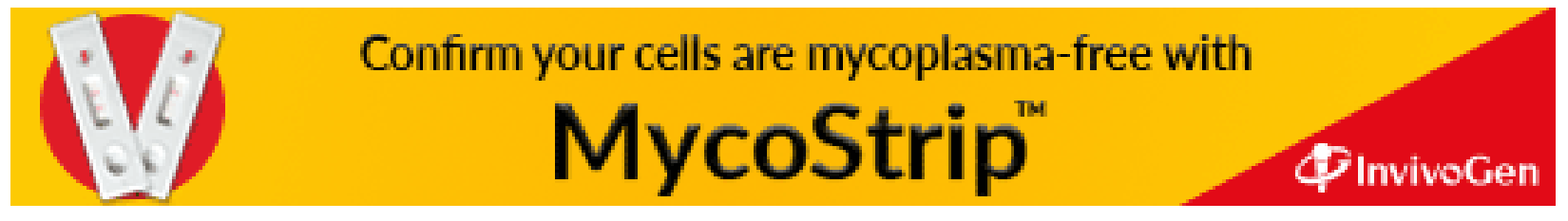

